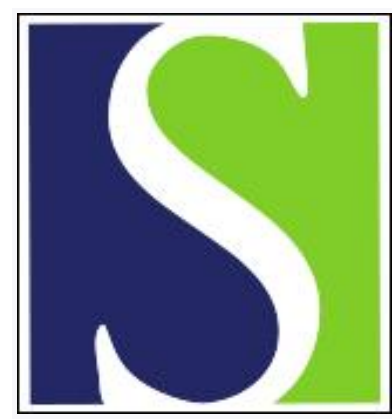

Scand J Work Environ Health 1981;7(1):56-61

https://doi.org/10.5271/sjweh.2565

Issue date: Mar 1981

Interferences in the spectrophotometric S-diphenylcarbazide determination of environmental hexavalent chromium in a chromium and zinc plating plant.

by Carelli G, La Bua R, Rimatori V, Porcelli D, lannaccone A

Key terms: chromium; chromium plating plant; environmental hexavalent chromium; hexavalent chromium; industrial hygiene; interference; plating; S-diphenylcarbazide; spectrophotometric S-diphenylcarbazide; spectrophotometric S-diphenylcarbazide determination; zinc; zinc plating plant

This article in PubMed: www.ncbi.nlm.nih.gov/pubmed/7313611 


\title{
Interferences in the spectrophotometric S-diphenylcarbazide determination of environmental hexavalent chromium in a chromium and zinc plating plant
}

by Giovanni Carelli, DSc, Roberto La Bua, DSc, Valentino Rimatori, DSc, Domenico Porcelli, BSc, Angelo lannaccone, MD ${ }^{1}$

\begin{abstract}
CARELLI G, LA BUA R, RIMATORI V, PORCELLI D, IANNACONE A. Interferences in the spectrophotometric S-diphenylcarbazide determination of environmental hexavalent chromium in a chromium and zinc plating plant. Scand $j$ work environ health 7 (1981) 56-61. A study on the determination of environmental hexavalent chromium $[\mathrm{Cr}(\mathrm{VI})\rceil$ was carried out in a chromium and zinc plating plant. The atmospheric particulate was collected both on glass wool filters and with an electrostatic sampler; $\mathrm{Cr}(\mathrm{VI})$ was determined by the S-diphenylcarbazide method. The filtered and electrostatically collected $\mathrm{Cr}$ (VI) was extracted with both $1.4 \%$ sulfuric acid and $7 \%$ sodium carbonate. Strong interference was observed when extraction was carried out with the acid medium. Alkaline extraction permits $95 \pm 6$ ( \pm SD) $\%$ recovery of the total chromium and has been shown to be suitable in releasing $\mathrm{Cr}$ (VI). The analyses of the alkaline samples were carried out with the standard addition method to compensate for a depressive interference of $26 \pm 8( \pm \mathrm{SD}) \%$. The absorbance decrease of the $\mathrm{Cr}-\mathrm{S}-$ diphenylcarbazide complex is a time function, and it should be measured within a few minutes of the reagent addition.
\end{abstract}

Key terms: industrial hygiene.

Hexavalent chromium [Cr(VI)] is widely used in industrial processes such as plating, tanning, painting, pigment production, and metallurgy. Workers employed in these activities can undergo exposure, and the same risk can also exist for people living near plants lacking suitable air cleaning devices.

The industrial use of $\mathrm{Cr}(\mathrm{VI})$ involves chromate, bichromate and chromic anhy-

I Institute of Occupational Medicine, Faculty of Medicine, Catholic University of S Cuore, Rome, Italy.

Reprint requests to: Dr Giovanni Carelli, Istituto di Medicina del Lavoro, Università Cattolica del S Cuore, via della Pineta Sacchetti 644, I-00168 Roma, Italy. dride, which are reciprocally convertible according to the chemical environment in which they occur.

Toxic effects of $\mathrm{Cr}(\mathrm{VI})$ are a consequence of both its ready penetration into cell membranes and its strong oxidizing power. Exposure among workers accounts for ulcers and perforation of the nasal septum, rhinitis, sinusitis, laryngitis, asthma, acute chemical pneumonitis, and bronchiogenic carcinoma, which can be associated with inflammatory and ulcerative diseases of the gastrointestinal tract $(2,6)$.

According to studies on laboratory animals, the toxicity of trivalent chromium [Cr(III)] is differentiated and appears to 
be related to parenteral administration (7).

The different toxicological roles of $\mathrm{Cr}$ (VI) and $\mathrm{Cr}$ (III) and their frequent presence in polluted atmospheres require specific analytical methods for the determination of $\mathrm{Cr}(\mathrm{VI})$ in workrooms. Most current analytical procedures utilize S-diphenylcarbazide, which reacts with $\mathrm{Cr}(\mathrm{VI})$ to yield a colored complex with a characteristic absorption band between 400 and $640 \mathrm{~nm}$ with the maximum at $540 \mathrm{~nm}$ (4). Atomic absorption spectrophotometry can be also used successfully, but preliminary separation techniques, such as ion exchange (3) and reactive ion exchange chromatography (5), are often required. Although these methods have been described originally for the determination of $\mathrm{Cr}$ (VI) in aqueous solutions, they could also profitably be applied to atmospheric particulate analysis if appropriate changes were made.

Recently Thomsen et al (8) showed that traditional S-diphenylcarbazide methods cannot be applied generically. Sample preparation is a critical step and care must be taken to minimize $\mathrm{Cr}$ (VI) losses by precipitation or reduction. The authors therefore suggested a carbonate procedure which has proved suitable in preventing $\mathrm{Cr}$ (VI) losses during welding fume analyses.

This paper describes a study on the interference which has been found to occur during the determination of $\mathrm{Cr}(\mathrm{VI})$ with the S-diphenylcarbazide method in a chromium and zinc plating plant. The environmental $\mathrm{Cr}(\mathrm{VI})$ concentrations are also reported.

The interference was studied through the extraction of $\mathrm{Cr}(\mathrm{VI})$ according to the methods of Abell \& Carlberg (1) and Thomsen \& Stern (8), which use dilute sulfuric acid and $7 \%$ sodium carbonate, respectively, as the extractants.

Since trivalent iron [Fe(III)] and bivalent zinc [Zn(II)] were normally present in the particulate, their effect on the complexation reaction was separately investigated. The source of the two metals was the process itself, the welding and grinding in the galvanic plant, and the emissions of a nearby ironworks. The effect of bivalent iron on the S-diphenylcarbazide reaction has been reported by Thomsen \& Stern (8).

\section{Material and methods}

\section{Particulate collection}

Airborne particulate was collected with the following sampling devices: glass wool (Gelman, Microquartz, $0.3 \mu \mathrm{m}$ pore size, $47 \mathrm{~mm}$ diameter) connected to a $10 \mathrm{l} / \mathrm{min}$ pump and a electrostatic sampler (model F, Mine Safety Appliances Co) at $12 \mathrm{KV}$.

\section{Instrumentation}

A Perkin-Elmer model 576 spectrophotometer was used, with a 1-cm light path, for the photometric measurements and the absorbance recordings at $540 \mathrm{~nm}$. A Perkin-Elmer model 403 atomic absorption spectrophotometer and a HGA-72 with a Hitachi model 56 potentiometric recorder were used for the total chromium and iron analyses.

\section{Standard solutions}

An aqueous hexavalent chromium (potassium dichromate) solution $(80 \mathrm{mg} / \mathrm{l})$ was used. Solutions of $\mathrm{Fe}$ (III) and $\mathrm{Zn}$ (II) $(1,000$ $\mathrm{mg} / \mathrm{l}$ ) in $1 \mathrm{~N}$ nitric acid were used for the interference study.

\section{Reagent}

Twenty milligrams of S-diphenylcarbazide were dissolved in $10 \mathrm{ml}$ of $95 \%$ ethyl alcohol, a solution was prepared by mixing with $4 \mathrm{ml}$ of concentrated sulfuric acid, and $36 \mathrm{ml}$ of demineralized water was added. The reagent was stored in a refrigerator and was stable for about one month.

\section{Interference study}

Preliminary $\mathrm{Cr}(\mathrm{VI})$ environmental determinations showed the following two distinct matrix interferences: (a) Absorbance of the complex $\mathrm{Cr}(\mathrm{VI})-\mathrm{S}$-diphenylcarbazide decreased as a function of time if $\mathrm{Cr}(\mathrm{VI})$ was extracted from the atmospheric particulate according to Thomsen \& Stern's method. (b) The absorbance depression was found to depend on the $\mathrm{Cr}(\mathrm{VI})$ extraction method used and could be essentially complete if Abell \& Carlberg's extractive method was used on these types of samples. Absorbance measurements were made at $540 \mathrm{~nm}$ for the evaluation of these effects. 
The role of $\mathrm{Fe}(\mathrm{III})$ and $\mathrm{Zn}$ (II) was first investigated for an explanation of the extent to which these metals were involved in effects $a$ and $b$. Since Fe(III) and $\mathrm{Zn}$ (II) standards were prepared in $1 \mathrm{~N}$ nitric acid, the complexation reactions were carried out in dilute nitric acid; nitric acid did not affect absorbance in the range of dilutions used, and its presence could be ignored.

Up to $1,000-\mu \mathrm{g}$ aliquots $(1,000 \mu \mathrm{l})$ of $\mathrm{Fe}$ (III) or $\mathrm{Zn}$ (II) standard solutions and 0.4 or $4.0 \mu \mathrm{g}$ ( 5 or $50 \mu \mathrm{l})$ of a $\mathrm{Cr}(\mathrm{VI})$ standard solution were placed in test tubes and diluted to $5 \mathrm{ml}$ with demineralized water. A $0.25-\mathrm{ml}$ aliquot of S-diphenylcarbazide reagent was added, and absorbance was measured. Table 1 shows the absorbance readings at $540 \mathrm{~nm} . \mathrm{T}=0$ corresponds to the time of the reagent addition. A $0.4-\mu$ g amount of $\mathrm{Cr}(\mathrm{VI})$ was chosen because it was the average content in the analytical aliquots. The results clearly show that the absorbance decrease was stronger if large amounts of $\mathrm{Fe}$ (III) were present. The $0.4-\mu \mathrm{g}$ amount of $\mathrm{Cr}(\mathrm{VI})$ gave practically constant absorbance readings up to $250 \mu \mathrm{g}$ of $\mathrm{Fe}$ (III) within $10 \mathrm{~min}$ after the reagent addition. Absorbance measurements should be made within $1 \mathrm{~min}$ in the presence of $500 \mu \mathrm{g}$ of $\mathrm{Fe}$ (III); slighter interferences were found to occur with $4.0 \mu \mathrm{g}$ of $\mathrm{Cr}$ (VI).

The effect on $0.4 \mu \mathrm{g}$ of $\mathrm{Cr}$ (VI) was negligible up to $500 \mu \mathrm{g}$ of $\mathrm{Zn}(\mathrm{II})$; however zinc could be ignored since its content was lower than $5 \mu \mathrm{g}$ in all the environmental samples.

Table 1 shows that $F e(I I I)$ has practically no role in interference type $b$. In order to characterize effect $b$, the study of the Cr(VI)-S-diphenylcarbazide reaction was carried out with the environmental matrix. $\mathrm{Cr}$ (VI) was determined for dust collected both in the electrostatic sampler and on the glass wool filters. The samples were alkaline- or acid-extracted prior to the analysis. The extractions were carried out according to the methods proposed by Thomsen \& Stern (8) and Abell \& Carlberg (1).

For the alkaline extraction and $\mathrm{Cr}$ (VI) determination, $3.5 \mathrm{mg}$ of dust collected with the electrostatic sampler or a glass wool filter (after $10 \mathrm{~m}^{3}$ sampling) were introduced into glass tubes, and $4 \times 2 \mathrm{ml}$ of $7 \%$ sodium carbonate were added. The tubes were transferred to a heated block at $120^{\circ} \mathrm{C}$, and digestion continued for 5 min, before dilution to $10 \mathrm{ml}$ with water. The suspension was filtered through a

Table 1. Effect of various amounts of trivalent iron [Fe (III)] on the absorbance of the $\mathrm{Cr}(\mathrm{VI})-\mathrm{S}$ diphenylcarbazide complex. [Cr(VI) = hexavalent chromium]

\begin{tabular}{|c|c|c|c|c|c|c|c|c|}
\hline \multirow{2}{*}{$\begin{array}{l}\text { Time after } \\
\text { reagent } \\
\text { addition }\end{array}$} & \multicolumn{8}{|c|}{ Micrograms of $\mathrm{Fe}(\mathrm{III})$ added } \\
\hline & 0 & 10 & 25 & 50 & 100 & 250 & 500 & 1,000 \\
\hline \multicolumn{9}{|l|}{ Two minutes } \\
\hline $0.4 \mu \mathrm{g} \mathrm{Cr}(\mathrm{VI})$ & 0.064 & 0.064 & 0.063 & 0.061 & 0.063 & 0.063 & 0.057 & 0.056 \\
\hline $4.0 \mu \mathrm{g} \mathrm{Cr}(\mathrm{VI})$ & 0.556 & - & & 0.558 & 0.553 & 0.540 & 0.534 & 0.528 \\
\hline \multicolumn{9}{|l|}{ Ten minutes } \\
\hline $0.4 / \mu \mathrm{g} \mathrm{Cr}(\mathrm{VI})$ & 0.064 & 0.064 & 0.064 & 0.064 & 0.064 & 0.059 & 0.050 & 0.048 \\
\hline $4.0 \mu \mathrm{g} \operatorname{Cr}(V I)$ & 0.556 & - & - & 0.558 & 0.547 & 0.534 & 0.521 & 0.509 \\
\hline \multicolumn{9}{|l|}{ Twenty minutes } \\
\hline $0.4 \mu \mathrm{g} \mathrm{Cr}(\mathrm{VI})$ & 0.064 & 0.064 & 0.064 & 0.064 & 0.063 & 0.056 & 0.047 & 0.044 \\
\hline $4.0 u \mathrm{~g} \mathrm{Cr}(\mathrm{VI})$ & 0.556 & - & - & 0.558 & 0.540 & 0.521 & 0.500 & 0.484 \\
\hline \multicolumn{9}{|l|}{ Thirty minutes } \\
\hline $0.4 u \mathrm{~g} \mathrm{Cr}(\mathrm{V} \mathrm{I})$ & 0.064 & 0.064 & 0.064 & 0.064 & 0.061 & 0.055 & 0.044 & 0.041 \\
\hline $4.0 \mu \mathrm{g} \mathrm{Cr}(\mathrm{VI})$ & 0.556 & - & - & 0.552 & 0.531 & 0.509 & 0.488 & 0.466 \\
\hline \multicolumn{9}{|l|}{ Forty minutes } \\
\hline $0.4 \mu \mathrm{g} \mathrm{Cr}(\mathrm{Vl})$ & 0.064 & 0.064 & 0.064 & 0.064 & 0.060 & 0.054 & 0.042 & 0.039 \\
\hline $4.0 \mu \mathrm{g} \mathrm{Cr}(\mathrm{VI})$ & 0.556 & 一 & 一 & 0.543 & 0.522 & 0.500 & 0.475 & 0.453 \\
\hline \multicolumn{9}{|l|}{ Fifty minutes } \\
\hline $0.4 \mu \mathrm{g} \operatorname{Cr}(V I)$ & 0.064 & 0.064 & 0.064 & 0.063 & 0.058 & 0.053 & 0.040 & 0.037 \\
\hline $4.0 \mu \mathrm{g}$ Cr(VI) & 0.556 & - & - & 0.534 & 0.516 & 0.484 & 0.463 & 0.441 \\
\hline \multicolumn{9}{|l|}{ Sixty minutes } \\
\hline $0.4 \mu \mathrm{g} \mathrm{Cr}(\mathrm{VI})$ & 0.064 & 0.063 & 0.063 & 0.061 & 0.057 & 0.052 & 0.038 & 0.035 \\
\hline $4.0 \mu \mathrm{g}$ Cr(vI) & 0.556 & 一 & - & 0.528 & 0.506 & 0.475 & 0.450 & 0.428 \\
\hline
\end{tabular}


cellulose membrane filter. The blank was prepared through the extraction of a clean glass wool filter. A 4-ml aliquot of the filtered sample was placed in a test tube, and $0.75 \mathrm{ml}$ of water and $0.25 \mathrm{ml}$ of concentrated sulfuric acid were added. S-diphenylcarbazide reagent $(0.25 \mathrm{ml})$ was added after being degassed by centrifugal agitation. A standard addition of $0.4 \mu \mathrm{g}$ of $\mathrm{Cr}$ (VI) (5 $\mu \mathrm{l}$ of the standard solution) was made to a 4-ml aliquot of the sample. Analysis was carried out from the addition after $1 \mathrm{~h}$ so the added $\mathrm{Cr}$ (VI) could equilibrate with the sample matrix. For the reference standard $1.55 \mathrm{ml}$ of water, $3.2 \mathrm{ml}$ of $7 \%$ sodium carbonate, and 0.25 $\mathrm{ml}$ of concentrated sulfuric acid were introduced into a test tube. After degassation, $0.4 \mu \mathrm{g}$ of $\mathrm{Cr}(\mathrm{VI})$ was added, and the color was developed after $1 \mathrm{~h}$.

The acid extraction was carried out according to the carbonate procedure with the difference that $1.4 \%$ sulfuric acid was used at room temperature as the extractant and the $0.25-\mathrm{ml}$ aliquot of concentrated sulfuric acid was replaced with $0.25 \mathrm{ml}$ of demineralized water.

Fig 1 and 2 show typical absorbance tracings of the $\mathrm{Cr}(\mathrm{VI})$-S-diphenylcarbazide complex. The graphs show that absorbance was a function of the time elapsed from the addition of the S-diphenyloarbazide reagent. The absorbance of alkaline extracts reached maximum after $2 \mathrm{~min}$ and was constant for about $3 \mathrm{~min}$. An absorbance decrease was observed 5 min after the addition.

A comparison between $\mathrm{E}$ and $\mathrm{G}$ ascribes the absorbance decrease merely to the interference effect of sodium carbonate. Fig 2 clearly shows that environmental $\mathrm{Cr}$ (VI) cannot be detected if acid extraction is carried out ( $\mathrm{C}^{2}$ and $\left.\mathrm{C}^{\prime}\right)$. The results were coincident for the filter and electrostatic samples. The fact that the additional $\mathrm{Cr}(\mathrm{VI})$ was undetected in $\mathrm{D}$ and $\mathrm{D}^{\prime}$ confirms the strong interference matrix effect observed in $\mathrm{C}$ and $\mathrm{C}^{\prime}$.

$\mathrm{Cr}$ (VI) additions to alkaline-extracted samples (A, A', B \& B' in fig 1 \& 2) showed only a slight depressive interference, which could be compensated for with the use of the standard addition method. The average depressive interference on 50 samples collected in various worksites of the plant after alkaline extraction was $26 \pm 8$ ( $\pm \mathrm{SD}) \%$. The $\mathrm{Cr}(\mathrm{VI})$ air concen- tration ranged between 0.02 and $0.69 \mu \mathrm{g} /$ $\mathrm{m}^{3}$, the average ( $\pm \mathrm{SD}$ ) being $0.17( \pm 0.16)$. These values are lower than those reported elsewhere (1) and can be explained by the strong air removal (about $10^{4} \cdot \mathrm{m}^{3}$ / h) on the edges of the chromium cells.

Three to four milligrams of the particulate collected with the electrostatic sam-

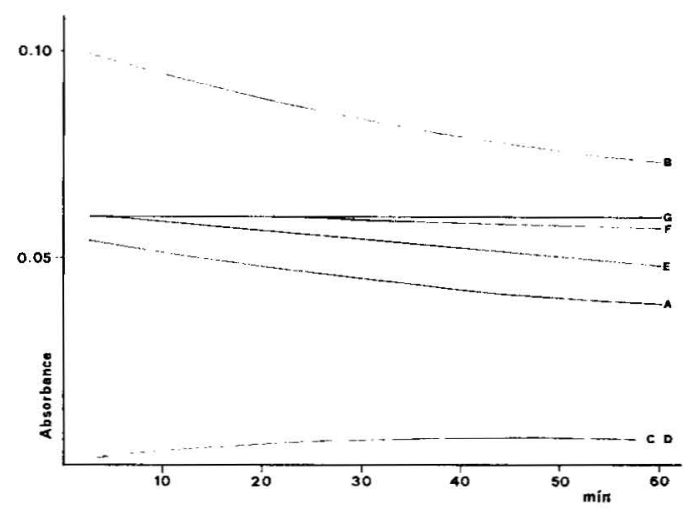

Fig 1. Typical absorbance tracings of the hexavalent chromium $[\mathrm{Cr}(\mathrm{VI})]$. A: electrostatically collected dust, $7 \%$ sodium carbonate extraction; $\mathrm{B}$ : as $\mathrm{A}+0.4 \mu \mathrm{g} \mathrm{Cr}(\mathrm{VI})$; $\mathrm{C}$ : electrostatically collected dust, $1.4 \%$ sulfuric acid extraction; $\mathrm{D}$ : as $\mathrm{C}+0.4 \mu \mathrm{g} \mathrm{Cr}(\mathrm{VI}) ; \mathrm{E}: 0.4 \mu \mathrm{g} \mathrm{Cr}(\mathrm{VI})$ in $7 \%$ sodium carbonate; $\mathrm{F}$ : $0.4 \mathrm{\mu g} \mathrm{Cr}(\mathrm{VI})$ in $1.4 \%$ sulfuric acid; $\mathrm{G}: 0.4 \mu \mathrm{g} \mathrm{Cr}(\mathrm{VI})$ in aqueous solution.

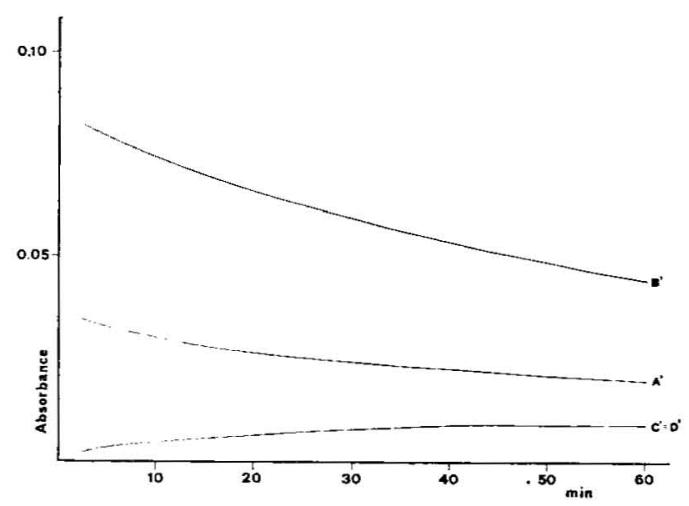

Fig 2. Typical absorbance tracings of the hexavalent chromium $[\mathrm{Cr}(\mathrm{VI})]$. A': glass wool filter collected dust, $7 \%$ sodium carbonate extraction; $\mathrm{B}^{\prime}$ : as $\mathrm{A}^{\prime}+0.4 \mu \mathrm{g} \mathrm{Cr}(\mathrm{VI})$; $\mathrm{C}^{\prime}$ : glass wool filter collected dust, $1.4 \%$ sulfuric acid extraction; $\mathrm{D}^{\prime}$ : as $\mathrm{G}^{\prime}+0.4 \mu \mathrm{g} \mathrm{Cr}(\mathrm{VI})$. 
Table 2. Acid and alkaline extractions: Total amounts of iron extracted from the environmental dust collected with the electrostatic sampler.

\begin{tabular}{|c|c|c|}
\hline \multirow{2}{*}{$\begin{array}{l}\text { Environmental } \\
\text { dust } \\
\text { (mg) }\end{array}$} & \multicolumn{2}{|c|}{ Total iron (mg) } \\
\hline & $\begin{array}{c}\text { Acid } \\
\text { extraction }\end{array}$ & $\begin{array}{c}\text { Alkaline } \\
\text { extraction }\end{array}$ \\
\hline $\begin{array}{l}3.52 \\
3.21\end{array}$ & $\begin{array}{l}0.0024 \\
0.0036\end{array}$ & \\
\hline $\begin{array}{l}3.50 \\
3.57\end{array}$ & & $\begin{array}{l}0.118 \\
0.111\end{array}$ \\
\hline
\end{tabular}

pler were dissolved with $2 \mathrm{ml}$ of a nitric and sulfuric acid mixture $(5: 2)$ at $140^{\circ} \mathrm{C}$. The digestion was continued until the volume was about $0.2 \mathrm{ml}$. The sample was then diluted to $5 \mathrm{ml}$ with demineralized water, and total chromium and iron were determined by flameless and flame atomic absorption spectrophotometry, respectively, by the recommended procedure. The $\mathrm{Cr}$ (VI) was $95 \pm 6( \pm \mathrm{SD}) \%$ of the total chromium determined by flameless atomic absorption spectrophotometry.

Table 2 shows the result of the determinations of total iron in the acid and alkaline extracts of about $3.5 \mathrm{mg}$ of environmental particulate collected with the electrostatic sampler. The alkaline procedure almost entirely prevented iron dissolution. The results were in agreement with similar determinations carried out on glass wool filters with $3-4 \mathrm{mg}$ of dust and $0.10-0.14 \mathrm{mg}$ of iron per filter.

\section{Discussion}

The strong depressive effect observed in the acid extracts cannot be explained on the basis of a massive extraction of iron. The analytical aliquots $(4 \mathrm{ml})$ used in the colorimetric reaction contained less than $50 \mu \mathrm{g}$ of iron, which would create, in the trivalent state, only negligible interference, as shown in table 1. One thousand micrograms of $\mathrm{Zn}$ (II) have been proved not to interfere in the determination of $0.4 \mu \mathrm{g}$ of $\mathrm{Cr}(\mathrm{VI})$. Preliminary X-ray diffractometric studies and microscopic analyses were used to assess the presence of coal, Fe(III) oxides, calcium carbonate, and calcium silicates in the environmental particulate. Since magnetite was not de- tected, we were not able to ascribe the strong depressive interference to $\mathrm{Fe}$ (II) originating from the acid treatment. Further studies are nevertheless necessary in order to exclude the possibility of any role of magnetite. A reduction of $\mathrm{Cr}(\mathrm{VI})$ by coal or other substances could partially explain the strong depression of the absorbance in dilute sulfuric acid. Interactions probably occur between unknown substances of the matrix and $\mathrm{Cr}(\mathrm{VI})$ without change in the hexavalent state (eg, ion exchange or adsorption). The interactions could be eliminated with alkaline extraction, except for a residual, moderate, depressive effect, which could be ascribed to a direct interference on the complexation reaction between chromium and S-diphenylcarbazide. This hypothesis could also support the fact that the $\mathrm{Cr}$ (VI) added to acid extracts was not detected.

\section{Conclusions}

The S-diphenyloarbazide method for the determination of $\mathrm{Cr}(\mathrm{VI})$ is not always reliable. The best extractive medium and matrix interferences should be carefully evaluated when environmental $\mathrm{Cr}(\mathrm{VI})$ is being checked.

During an environmental investigation of a chromium and zinc plating plant, we have shown that $\mathrm{Cr}(\mathrm{VI})$ acid extraction gives rise to an erroneous determination of the $\mathrm{Cr}(\mathrm{VI})$ content of these environmental samples due to an enhancement of the matrix effect which leads to a significant reduction in the measured $\mathrm{Cr}$ (VI) content. The procedure proposed by Thomsen \& Stern (8) for welding fumes analyses appears to be reliable, provided that the standard addition method is applied and that absorbance measurements are made within the time limits suggested by the evaluation of the absorbance tracings of the $\mathrm{Cr}(\mathrm{VI})-\mathrm{S}-$ diphenylcarbazide complex.

\section{References}

1. Abell MT, Carlberg JR. A simple reliable method for the determination of airborne hexavalent chromium. Am ind hyg assoc $\mathbf{j}$ 35 (1974) 229-233.

2. Brinton HP, Frasier ES. Morbidity and mortality experience among chromate work- 
ers. Publ health rept 67 (1952) 835-847.

3. Cresser MS, Hargitt R. The determination of Chromium (III) and Chromium (VI) by total anion exchange and atomic absorption spectrometry. Anal chim acta 81 (1976) 196-198.

4. Ege JF Jr, Silverman L. A stable colorimetric reagent for chromium. Ind eng chem anal ed 19 (1947) 693-697.

5. Lin JW, Janauer JE. Selective separations by reactive ion exchange: Part III. Preconcentration and separations of oxo anions. Anal chim acta 79 (1975) 219-227.

Received for publication: 23 October 1980
6. Manusco TF. Occupational cancer and other health hazards in a chromate plant: A medical appraisal: II. Chemical and toxicological aspects. Ind med surg 20 (1951) 393-407.

7. Mertz W, Roginski EE, Reba RC. Biological activity and fate of intravenous chromium (III) in the rat. Am $\mathrm{j}$ physiol 209 (1965) $489-494$.

8. Thomsen E, Stern RM. A simple analytical technique for the determination of hexavalent chromium in welding fumes and other complex matrices. Scand $j$ work environ health 5 (1979) 386-483. 